\title{
A lack of consideration of a dose-response relationship can lead to erroneous conclusions regarding $100 \%$ fruit juice and the risk of cardiometabolic disease
}

\author{
Tauseef A. Khan $\mathbb{1}^{1,2} \cdot$ Laura Chiavaroli ${ }^{1,2} \cdot$ Andreea Zurbau ${ }^{1,2} \cdot$ John L. Sievenpiper $\mathbb{C}^{1,2,3,4,5}$
}

Received: 23 July 2019 / Revised: 10 September 2019 / Accepted: 27 September 2019 / Published online:

(c) The Author(s) 2019. This article is published with open access

\section{Sugar-sweetened beverages and $100 \%$ fruit juice: a tale of two dose-response analyses}

Excess intake of added sugars especially from sugarsweetened beverages (SSBs) is associated with increased risk of obesity, type 2 diabetes, cardiovascular disease (CVD) and mortality [1]. Mounting evidence suggests that SSBs contribute a substantial proportion of daily intake of sugars [2] while offering no nutritional benefit; and it is the obesogenic effect of excess calories that increases the risk of cardiometabolic disease and mortality rather than any adverse effect of fructose-containing sugars [3]. The consistent relationship between SSBs and cardiometabolic disease outcomes in several large cohorts has shaped public health guidelines calling for the reduction of SSBs [4] and has resulted in a soda-tax within several countries.

In contrast to SSBs, whole fruits have always been a component of a healthy dietary pattern and its liquid form, $100 \%$ fruit juice, is also included as an option to meet the recommended targets for fruit and vegetable intake in some nutrition guidelines globally (https://www.nhs.uk/live-well/

$\bowtie$ John L. Sievenpiper

john.sievenpiper@utoronto.ca

1 Department of Nutritional Sciences, Faculty of Medicine, University of Toronto, Toronto, ON, Canada

2 Toronto 3D Knowledge Synthesis and Clinical Trials Unit, Clinical Nutrition and Risk Factor Modification Centre, St. Michael's Hospital, Toronto, ON, Canada

3 Division of Endocrinology and Metabolism, Department of Medicine, St. Michael's Hospital, Toronto, ON, Canada

4 Li Ka Shing Knowledge Institute, St. Michael's Hospital, Toronto, ON, Canada

5 Department of Medicine, Faculty of Medicine, University of Toronto, Toronto, ON, Canada eat-well/5-a-day-what-counts/). However, recently there have been attempts to group 100\% fruit juices and SSBs as "sugary drinks" [5] as both have similar energy densities: A typical $250 \mathrm{ml}$ of $100 \%$ orange juice contains $110 \mathrm{kcal}$ and $26 \mathrm{~g}$ of sugar; $250 \mathrm{ml}$ of soda contains $105 \mathrm{kcal}$ and $26.5 \mathrm{~g}$ of sugar. While equating SSBs and $100 \%$ fruit juice on sugar content makes logical sense, especially when we consider that liquid calories are less likely to be compensated [6], it ignores the fact that $100 \%$ fruit juice, in a similar manner to fruit, also provides health-promoting micronutrients such as vitamins, minerals and polyphenols which have health protective effects [7]. The question remains as to whether there is any evidence demonstrating an association between $100 \%$ fruit juice and cardiometabolic disease that is similar to that found with SSBs. Seeking a simple binary answer of harm or benefit would be overly simplistic as it disregards the complex relationships that exists between various foods, their nutrient matrix and disease. We propose that the evidence needed to assess if $100 \%$ fruit juices are similar to SSBs require us to understand the population level dose-response relationships.

Using aggregate data from categorical tables of three separate published studies reporting on disease associations for SSBs, $100 \%$ fruit juice or both ("sugary drinks"), we modelled a non-linear dose-response using the best fitting second-order fractional polynomial regression [8]. In Fig. 1a, using data from the Health Professionals' Follow-up Study and the Nurses' Health Study, the dose-response association of SSBs with total mortality follows a linear model: [9]. A similar linear dose-response is also found in other prospective cohort studies assessing the relationship between SSBs and CVD mortality [9], type 2 diabetes [10], metabolic syndrome [11] and hypertension [12]. Therefore, studies are correct in reporting disease associations for SSBs as linear analyses or highlight extreme comparisons, which assumes linearity, because the results are consistent with the linear risk curve across the whole dose range. 

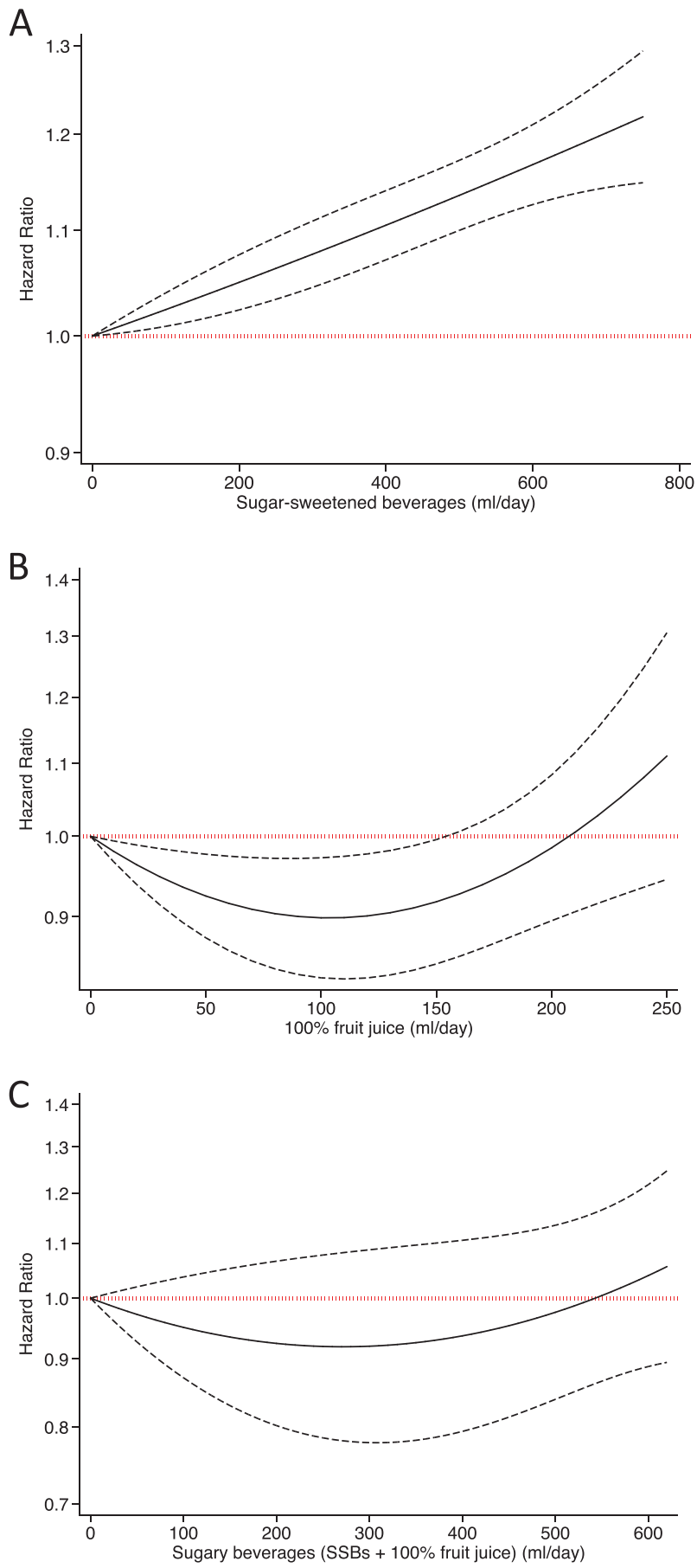

Fig. 1 Dose-response relationship of a. SSBs with total mortality [9], b. $100 \%$ fruit juice with CVD incidence [13] and c. sugary beverages (SSBs $+100 \%$ fruit juice) with total mortality [5]. For each study we modelled the non-linear dose-response using the best fitting secondorder fractional polynomial regression using summarised data [8]

However, this is not the case with $100 \%$ fruit juice. In Fig. $1 \mathrm{~b}$, data analysed from a large European cohort [13] demonstrate a non-linear J-shaped curve, revealing a protective association between 100\% fruit juice and CVD incidence at moderate doses but indicating harm at higher doses. The curve demonstrates a maximum benefit at doses from 100 to $150 \mathrm{ml} /$ day, which is equal to a small glass of $100 \%$ fruit juice. Similar non-linear protective associations at moderate doses for $100 \%$ fruit juice consumption are also seen with stroke [13], type 2 diabetes [10], metabolic syndrome [14] and hypertension [15] (there are no studies reporting an association between $100 \%$ fruit juice and total mortality). Therefore, reporting linear or extreme comparison analysis that assumes linearity between $100 \%$ fruit juice and cardiometabolic disease outcomes would be incorrect. The results from such analyses would only apply at high intakes and the overall conclusions reached would be spurious as they mask any protective associations at moderate doses.

In a recent article by Collins et al. [5], using data from the REGARDS cohort in USA, the authors used a linear analysis and concluded that each additional 12-oz serving of $100 \%$ fruit juice per day is associated with higher all-cause mortality. Since $75 \%$ of the cohort consumed less than $8-0 z$ daily, the result from this analysis was likely driven by a limited number of extreme consumers of $100 \%$ fruit juice. Furthermore, the authors did not provide information on $100 \%$ fruit juice consumption to assess a dose-response relationship. Instead, data were reported as categorised energy groups for "sugary beverages"-a combination of $100 \%$ fruit juice and SSBs. In Fig. 1c, using data for sugarybeverages, we show that the best-fit relationship, for sugary beverages and total mortality, is nearly $\mathrm{J}$-shaped, suggesting a protective association, albeit non-significant, at moderate doses. Visually, this curve lies in between the linear dose-response of SSBs (Fig. 1a) and non-linear dose-response of $100 \%$ fruit juice (Fig. 1b) suggesting an influence of $100 \%$ fruit juice at moderate doses. The potential benefit of $100 \%$ fruit juice seen at moderate doses may be the result of the range of nutrients and bioactive compounds within the juice. However, the potential for harm at higher doses may be due to the consumption of excess calories outweighing any benefit of the nutrients contained within $100 \%$ fruit juice. By combining SSBs and $100 \%$ fruit juice, Collins et al. ignored the prevailing independent dose-response curves of each food source. In conclusion, these three examples indicate that SSBs and $100 \%$ fruit juice have different dose-response relationships and a lack of consideration of such relationships can lead to inaccurate reporting and erroneous conclusions especially regarding 100\% fruit juice and cardiometabolic disease.

\section{The simple model for sugar-sweetened beverages}

When assessing the relationship between food and disease, a linear analysis is routinely carried out as it is the simplest model that can represent the data. For example, if an 
analysis between a food source of sugars and total mortality shows a significant harmful association in a per-dose analysis, it comes with an implicit assumption that the risk association is linear throughout the dose range and there is no level of exposure at which the association is null or protective. This assumption has important implications for developing guidelines and associated policy for particular foods. As SSBs consistently show an increasing association throughout the investigated dose ranges in large prospective cohort studies, guidelines to reduce its intake is sensible and based upon a demonstrated linear dose-response relationship. However, when the true underlying association is nonlinear, as is the case with $100 \%$ fruit juice, it is inaccurate to represent the association as a per-dose analysis. Such oversimplistic representation of the overall association that ignores the non-linearity in the dose-disease relationship can easily result in misleading conclusions. The adage attributed to Einstein applies here: "Everything must be made as simple as possible, but not one bit simpler" [16]. In the case of a non-linear association, the "dose-response" model itself is the simple model of the underlying association; forcing an even simpler linear model that the data do not support would be a fallacy.

\section{Dose-response relationship in nutrition research: the next frontier}

Non-linear association are well established for essential nutrients following a U-shaped relationship curve in which low dose is harmful due to deficiency, intermediate dose (or replete states) elicit positive health effects and high doses are harmful because of toxicity (https://ods.od.nih.gov/Hea 1th_Information/Dietary_Reference_Intakes.aspx). Foods, which contain essential nutrients, can thus be reasonably expected to follow non-linear associations with health outcomes as well. Having said that, the reporting of non-linear dose-response association the literature for major food sources investigating cardiometabolic disease leaves much to be desired. A majority of prospective cohort studies investigating diet and disease start with linearity as the primary model and denote harm or protective associations to various foods without investigating the subtle relationships of disease with dose ranges-which might be nonlinear. Their conclusions are focused upon a linear dose-response or an extreme comparison of categorical groups (e.g. quantiles) that also implies linearity, while often the associated categorical tables suggest non-linearity. Although the linear association might hold true for extreme intakes, ignoring the nuanced relationship of the dose range is one reason why the science of nutrition is facing many challenges especially in reporting numerous contradictory results using linear analyses [17]. These results might simply be a result of applying the incorrect linear model to a non-linear association, an inability to assess non-linearity due to the lack of power, or a difference in population dose ranges. In the latter case, depending upon the dose range observed, one can expect divergent results from studies conducted in different populations as each would be assessing a limited portion of a true non-linear curve.

A complete dose-response analysis in a prospective cohort study should include exploring doses and dose ranges that are protective or harmful, with threshold or plateau effects, and examining differences between moderate and high intakes. In fact, further analyses can be performed to see if dose ranges differ for populations, ethnicities, ages, health status, sex, demographics or any other important characteristics. The dose-response analysis can also drive insights into mechanisms by exploring why such non-linear associations exist in the first place: what drives the neutral, protective and harmful effects; why are there different effects at low, moderate and high doses; does excessive calories overwhelm the protective effect of beneficial nutrients; how does the nutrient matrix within foods affect dose-response relationships; and is there an underlying biological or evolutionary mechanism for such non-linear effects, e.g. hormesis [18]. The importance of dose-response analyses to further the field of nutrition cannot be understated. In fact, writing in the journal Science the Global Panel on Agriculture and Food Systems for Nutrition in their global research agenda for nutrition highlighted the need for a "better understanding of dose-response relationships" of foods which will enable us to agree on what constitutes a healthy diet and denoted it as one of the top ten research priorities for the upcoming decade [19].

As the case of $100 \%$ fruit juice above exemplifies, it is vitally important to explore and report the full dose-response in prospective cohort studies rather than a linear analysis. In-fact many nutrients and foods have reported non-linear relationships with cardiometabolic disease outcomes including fruit [20], nuts [20], salt [21], coffee [22], dairy [20], unprocessed red meat [20], whole grains [20] and total carbohydrates [23]. However, only a few authors have attempted to make informed interpretations of non-linear dietary data in a population context for cardiometabolic disease [21,23].

There are now several methods to study underlying nonlinear dose-response associations in prospective cohort studies using restricted cubic splines, fractional polynomials and categorical modelling [24]. New methods are also available to combine dose-response analyses in meta-analysis [25]. While it's true that modelling dose-response is complex, and reporting standards do not yet give any concrete instructions on how best to report non-linear dose-response associations, we simply cannot ignore the elephant in the room i.e. the realisation that the relationship might not be linear. 


\section{Conclusion}

The concern regarding dietary sugars continues to grow and $100 \%$ fruit juice is now being discouraged by health agencies due to its high sugar content [4]. Even public perception of $100 \%$ fruit juice has been shifting to equate it with SSBs (https://www.nytimes.com/2018/07/07/opinion/ sunday/juice-is-not-healthy-sugar.html). We contend that this issue has arisen due to the lack of consideration for the dose-response association between $100 \%$ fruit juice and cardiometabolic disease. Investigators of prospective cohort studies studying beverages, but also other important food sources, should consider modelling dose-response associations with disease to see if they are non-linear. If so, then the identification of specific dose ranges or cut-offs for benefit and harm would have important implications for dietary guidelines and public policy. Failing to do so will only perpetuate the misinterpretation of the results in nutrition research leading to inaccurate conclusions regarding relationships between foods and health.

Acknowledgements We would like to thank Nema McGlynn (Department of Nutritional Sciences, University of Toronto) for her valuable comments.

Funding This work was supported by the Canadian Institutes of Health Research (funding reference number, 129920) through the Canada-wide Human Nutrition Trialists' Network (NTN). The Diet, Digestive tract and Disease (3-D) Centre, funded through the Canada Foundation for Innovation (CFI) and the Ministry of Research and Innovation's Ontario Research Fund (ORF), provided the infrastructure for the conduct of this project. TAK was funded by a Toronto 3D Postdoctoral Fellowship Award. LC is funded by a Mitacs Accelerate Postdoctoral Fellowship. JLS was funded by a Diabetes Canada Clinician Scientist Award.

Author contributions TAK conceived, wrote and revised the manuscript. LC, AZ and JLS contributed to the writing and critically revised the manuscript. All the authors gave their final approval.

\section{Compliance with ethical standards}

Conflict of interest TAK received unrestricted travel donation from Bee Maid Honey Ltd and was an invited speaker for the Calorie Control Council. JLS has received research support from the Canadian Foundation for Innovation, Ontario Research Fund, Province of Ontario Ministry of Research and Innovation and Science, Canadian Institutes of health Research (CIHR), Diabetes Canada, PSI Foundation, Banting and Best Diabetes Centre (BBDC), American Society for Nutrition (ASN), INC International Nut and Dried Fruit Council Foundation, National Dried Fruit Trade Association, The Tate and Lyle Nutritional Research Fund at the University of Toronto, The Glycemic Control and Cardiovascular Disease in Type 2 Diabetes Fund at the University of Toronto (a fund established by the Alberta Pulse Growers), and the Nutrition Trialists Fund at the University of Toronto (a fund established by an inaugural donation from the Calorie Control Council). He has received in-kind food donations to support a randomized controlled trial from the Almond Board of California, California Walnut Commission, American Peanut Council, Barilla,
Unilever, Unico/Primo, Loblaw Companies, Quaker, Kellogg Canada, and WhiteWave Foods. He has received travel support, speaker fees and/or honoraria from Diabetes Canada, Mott's LLP, Dairy Farmers of Canada, FoodMinds LLC, International Sweeteners Association, Nestlé, Pulse Canada, Canadian Society for Endocrinology and Metabolism (CSEM), GI Foundation, Abbott, Biofortis, ASN, Northern Ontario School of Medicine, INC Nutrition Research \& Education Foundation, European Food Safety Authority (EFSA), Comité Européen des Fabricants de Sucre (CEFS), and Physicians Committee for Responsible Medicine. He has or has had ad hoc consulting arrangements with Perkins Coie LLP, Tate \& Lyle, and Wirtschaftliche Vereinigung Zucker e.V. He is a member of the European Fruit Juice Association Scientific Expert Panel. He is on the Clinical Practice Guidelines Expert Committees of Diabetes Canada, European Association for the study of Diabetes (EASD), Canadian Cardiovascular Society (CCS), and Obesity Canada. He serves or has served as an unpaid scientific advisor for the Food, Nutrition, and Safety Program (FNSP) and the Technical Committee on Carbohydrates of the International Life Science Institute (ILSI) North America. $\mathrm{He}$ is a member of the International Carbohydrate Quality Consortium (ICQC), Executive Board Member of the Diabetes and Nutrition Study Group (DNSG) of the EASD, and Director of the Toronto 3D Knowledge Synthesis and Clinical Trials foundation. His wife is an employee of Sobeys Inc. AZ is a part-time employee at INQUIS Clinical Research, Inc., a contract research organisation. LC has no conflicts to disclose.

Publisher's note Springer Nature remains neutral with regard to jurisdictional claims in published maps and institutional affiliations.

Open Access This article is licensed under a Creative Commons Attribution 4.0 International License, which permits use, sharing, adaptation, distribution and reproduction in any medium or format, as long as you give appropriate credit to the original author(s) and the source, provide a link to the Creative Commons license, and indicate if changes were made. The images or other third party material in this article are included in the article's Creative Commons license, unless indicated otherwise in a credit line to the material. If material is not included in the article's Creative Commons license and your intended use is not permitted by statutory regulation or exceeds the permitted use, you will need to obtain permission directly from the copyright holder. To view a copy of this license, visit http://creativecommons. org/licenses/by/4.0/.

\section{References}

1. Prinz P. The role of dietary sugars in health: molecular composition or just calories? Eur J Clin Nutr. 2019;73:1216-1223.

2. Singh GM, Micha R, Khatibzadeh S, Shi P, Lim S, Andrews KG, et al. Global, regional, and national consumption of sugarsweetened beverages, fruit juices, and milk: a systematic assessment of beverage intake in 187 countries. PLoS One. 2015;10: e0124845.

3. Khan TA, Sievenpiper JL. Controversies about sugars: results from systematic reviews and meta-analyses on obesity, cardiometabolic disease and diabetes. Eur J Nutr. 2016;55:25-43.

4. World Health Organization. Guideline: sugars intake for adults and children. World Health Organization; 2015. https://www.who. int/nutrition/publications/guidelines/sugars_intake/en/.

5. Collin LJ, Judd S, Safford M, Vaccarino V, Welsh JA. Association of sugary beverage consumption with mortality risk in US adults: a secondary analysis of data from the REGARDS study. JAMA Netw Open. 2019;2:e193121. 
6. DiMeglio DP, Mattes RD. Liquid versus solid carbohydrate: effects on food intake and body weight. Int J Obes. 2000;24:794.

7. Clemens R, Drewnowski A, Ferruzzi MG, Toner CD, Welland D. Squeezing fact from fiction about $100 \%$ fruit juice. Adv Nutr. 2015;6:236s-243s

8. Crippa A, Discacciati A, Bottai M, Spiegelman D, Orsini N. Onestage dose-response meta-analysis for aggregated data. Stat Methods Med Res. 2019;28:1579-96.

9. Malik VS, Li Y, Pan A, De Koning L, Schernhammer E, Willett WC, et al. Long-term consumption of sugar-sweetened and artificially sweetened beverages and risk of mortality in US adults. Circulation. 2019;139:2113-25.

10. Eshak ES, Iso H, Mizoue T, Inoue M, Noda M, Tsugane S. Soft drink, $100 \%$ fruit juice, and vegetable juice intakes and risk of diabetes mellitus. Clin Nutr. 2013;32:300-8.

11. Mirmiran P, Yuzbashian E, Asghari G, Hosseinpour-Niazi S, Azizi F. Consumption of sugar sweetened beverage is associated with incidence of metabolic syndrome in Tehranian children and adolescents. Nutr Metab. 2015;12. https://doi.org/10.1186/ s12986-015-0021-6.

12. Cohen L, Curhan G, Forman J. Association of sweetened beverage intake with incident hypertension. J Gen Intern Med. 2012;27:1127-34.

13. Scheffers FR, Boer JMA, Verschuren WMM, Verheus M, van der Schouw YT, Sluijs I, et al. Pure fruit juice and fruit consumption and the risk of CVD: the European prospective investigation into cancer and nutrition-Netherlands (EPIC-NL) study. Br J Nutr. 2019;121:351-9.

14. Ferreira-Pêgo C, Babio N, Bes-Rastrollo M, Corella D, Estruch R, Ros E, et al. Frequent consumption of sugar- and artificially sweetened beverages and natural and bottled fruit juices is associated with an increased risk of metabolic syndrome in a mediterranean population at high cardiovascular disease risk. J Nutr. 2016;146:1528-36.

15. Auerbach BJ, Littman AJ, Tinker L, Larson J, Krieger J, Young B, et al. Associations of $100 \%$ fruit juice versus whole fruit with hypertension and diabetes risk in postmenopausal women: results from the women's health initiative. Preventive Med. 2017;105:212-8.

16. Einstein A, Dyson F. The ultimate quotable Einstein. Princeton University Press; 2013. https://press.princeton.edu/books/ha rdcover/9780691138176/the-ultimate-quotable-einstein.

17. Ioannidis JPA. Implausible results in human nutrition research. Brit Med J. 2013;347:f6698.

18. Hayes DP. Nutritional hormesis. Eur J Clin Nutr. 2007;61:147-59.

19. Haddad L, Hawkes C, Webb P, Thomas S, Beddington J, Waage $\mathrm{J}$, et al. A new global research agenda for food. Nat News. 2016;540:30.

20. Bechthold A, Boeing H, Schwedhelm C, Hoffmann G, Knüppel S, Iqbal K, et al. Food groups and risk of coronary heart disease, stroke and heart failure: a systematic review and dose-response meta-analysis of prospective studies. Crit Rev Food Sci Nutr. 2019;59:1071-90.

21. Mente A, O’Donnell M, Rangarajan S, McQueen M, Dagenais G, Wielgosz A, et al. Urinary sodium excretion, blood pressure, cardiovascular disease, and mortality: a community-level prospective epidemiological cohort study. Lancet. 2018;392:496-506.

22. Crippa A, Discacciati A, Larsson SC, Wolk A, Orsini N. Coffee consumption and mortality from all causes, cardiovascular disease, and cancer: a dose-response meta-analysis. Am J Epidemiol. 2014;180:763-75.

23. de Souza RJ, Dehghan M, Anand SS. Low carb or high carb? Everything in moderation ... until further notice. Eur Heart J. 2019;40:2880-2882. https://doi.org/10.1093/eurheartj/ehz269.

24. Boeing $H$. Nutritional epidemiology: new perspectives for understanding the diet-disease relationship? Eur J Clin Nutr. 2013;67:424-9.

25. Zhang C, Jia P, Yu L, Xu C. Introduction to methodology of doseresponse meta-analysis for binary outcome: with application on software. J Evid Based Med. 2018;11:125-9. 